\title{
IMMUNE RESPONSE TO CHEMICALLY MODIFIED FLAGELLIN
}

\author{
I. Induction of Antibody Tolerance to Flagellin by \\ Acetoacetrlated Derivatives of the Protein \\ By C. R. PARISH, Ph.D. \\ (From the Department of Microbiology, The John Curtin School of Medical Research, \\ The Australian National University, Canberra, A.C.T., Australia)
}

(Received for publication 23 February 1971)

One of the basic questions of immunology is what makes a good antigen? Why is it that some substances, such as the serum proteins, are comparatively poor at eliciting antibodies, whereas other substances, such as the bacterial proteins, are very good antibody inducers? From data presented by numerous workers it appears that for a substance to induce antibody formation two general properties are required. Firstly, the substance must possess chemical groupings (antigenic determinants) which are regarded as "foreign" by the injected animal, and secondly, the substance must be capable of stimulating the animal to produce antibodies against these foreign determinants (see reference 1). At present much is known about the physical and chemical nature of many antigenic determinants, particularly those of the simpler antigens, such as the carbohydrates (2-4) and synthetic polypeptides $(1,5,6)$. In contrast, little is known about those factors which enable an antigenic determinant to stimulate antibody formation.

Work in this laboratory has been directed towards determining some of the factors which influence the immunogenicity of antigens using the globular protein flagellin from Salmonella adelaide organisms as an antigen model. Flagellin (mol. wt. 40,000) has the advantage that it is highly immunogenic, injections of as little as $10 \mathrm{ng}$ in saline into rats producing detectable amounts of anti-flagellin antibody (7). On the other hand, partial degradation of the molecule with cyanogen bromide drastically reduces the antibody-forming capacity of the protein and produces a preparation with strong toleranceinducing properties $(8,9)$. Data presented in this paper demonstrate that by a process of acetoacetylation, even stronger tolerance-inducing preparations of flagellin can be obtained. Some preliminary aspects of this work have been reported elsewhere. ${ }^{1}$

${ }^{1}$ Parish, C. R. 1971. Suppression of antibody formation and concomitant enhancement of cell-mediated immunity by acetoacetylated derivatives of Salmonella flagellin. In Immunolgoical Tolerance to Microbial Antigens. H. Friedman, editor. Ann. N.Y. Acad. Sci. In press.

THE JOURNAL OF EXPERIMENTAL MEDICINE - vOLUME 134, 1971 


\section{Materials and Methods}

Animals.-Randomly bred Wistar rats of 6-10 wk of age and of either sex were used. Animals were obtained from a Wistar rat colony established from breeders supplied by the Walter and Eliza Hall Institute of Medical Research, Parkville, Australia. In all cases rats were bled from the tail.

Antisera against flagellin were raised in 6-month-old New Zealand rabbits.

Antigens.-Salmonella adelaide flagellin (strain SW1338; $\mathrm{H}$ antigen, $\mathrm{fg} ; 0$ antigen, 35) was prepared as reported elsewhere (10). A cyanogen bromide (CNBr) digest of $S$. adelaide flagellin was obtained as described previously (11). All injections were in saline into the hind footpads $(50 \mu l /$ footpad $)$.

Antisera to Flagellin.-Antisera were raised in rabbits by initially injecting $0.5 \mathrm{mg}$ of flagellin emulsified in Freund's complete adjuvant (FCA) ${ }^{2}$ at multiple, subcutaneous sites. Four wk later animals were challenged in a similar manner with $0.5 \mathrm{mg}$ of flagellin emulsified in Freund's incomplete adjuvant (FIA). Then, 2 wk later, the rabbits were injected intravenously with $0.5 \mathrm{mg}$ of flagellin in saline. All rabbits were bled 7-14 days after the final challenge. The antigenic studies presented in this paper were performed with antiserum (single bleed) from one hyperimmune rabbit. However, comparable results were obtained if other rabbit antisera were employed.

Conditions for Acetoacetylation of Flagellin.-S. adelaide flagellin was acetoacetylated with diketene (acetoacetic anhydride) according to a previously described method $(12,13)$. Flagellin $(5 \mathrm{mg} / \mathrm{ml})$ in $0.04 \mathrm{M}$ borate-boric acid buffer, $\mathrm{pH} 8.5$, was reacted with a 19-960 $\mathrm{M}$ excess of diketene (K \& K Labs, Inc., Plainview, N. Y.) for $6 \mathrm{hr}$ at $20^{\circ} \mathrm{C}$. It was assumed that liquid diketene was 24.4 M. After reaction, the solution was exhaustively dialyzed against multiple changes of distilled water for $24 \mathrm{hr}$ at $20^{\circ} \mathrm{C}$. Using aqueous $\mathrm{FeCl}_{3}$ solution the number of acetoacetyl groups attached was measured spectrophotometrically (13). The molar extinction coefficient of the acetoacetyl group in the presence of $\mathrm{FeCl}_{3}$ was 371 at $540 \mathrm{~nm}$.

Acetoacetyl groups bound to residues other than amino groups were removed by treating preparations with $0.2 \mathrm{M} \mathrm{NaHCO}-\mathrm{Na}_{2} \mathrm{CO}_{3}$ buffer at $\mathrm{pH} 9.5$ for $18 \mathrm{hr}$ at $20^{\circ} \mathrm{C}$ (13). Buffer and reactants were then removed by dialysis against distilled water $\left(24 \mathrm{hr}, 20^{\circ} \mathrm{C}\right)$. All acetoacetyl groups were removed by treating the acetoacetylated flagellins with a 10 -fold molar excess of hydroxylamine $\left(\mathrm{pH} 7,20^{\circ} \mathrm{C}, 24 \mathrm{hr}\right)$ with respect to the number of acetoacetyl groups attached (13). Reactants were removed by dialysis.

Dinitrophenylation of Flagellin.-The extent of acetoacetylation of lysyl amino groups was determined by amino acid analysis of dinitrofluorobenzene (DNFB) reacted protein. Approximately $200 \mu \mathrm{g}$ of acetoacetylated flagellin was dissolved in $100 \mu \mathrm{l}$ of $0.1 \mathrm{M}, \mathrm{NaHCO}-\mathrm{Na}_{2} \mathrm{CO}_{3}$ buffer, $\mathrm{pH} 9.5$, and reacted with $5 \mu \mathrm{I}$ of DNFB $\left(190 \mathrm{mg} / \mathrm{ml}\right.$ in acetone) for $1 \mathrm{hr}$ at $37^{\circ} \mathrm{C}$ in the dark. An additional $5 \mu \mathrm{l}$ of DNFB was then added and the mixture left to react for another hour. Under these conditions all the lysines and methyl lysines of flagellin were dinitrophenylated whereas acetoacetylated lysines (and methyl lysines) were not substituted. The dinitrophenylated protein was precipitated by the addition of $0.9 \mathrm{ml}$ of $10 \%$ trichloroacetic acid, pelleted by centrifugation $(3000 \mathrm{~g}, 10 \mathrm{~min}$ ), and washed twice with $0.9 \mathrm{ml}$ of $1 \mathrm{~N} \mathrm{HCI}$. The precipitate was then hydrolysed in the presence of $0.5 \mathrm{ml}$ of $5.54 \mathrm{~N} \mathrm{HCl}$ (constant boiling) at $110^{\circ} \mathrm{C}$ for $4 \mathrm{hr}$. For convenience and to avoid Iosses of material, the same tube was used for dinitrophenylation, centrifugation, and hydrolysis.

Hydrolysates were applied to a Technicon amino acid analyzer (Technicon Corp., Tarry-

${ }^{2}$ Abbreviations used in this paper: DNFB, dinitrofluorobenzene; $\Delta \mathrm{F}_{\mathrm{rel}}$, average free energy of binding; FCA, Freund's complete adjuvant; FIA, Freund's incomplete adjuvant; $\mathbf{K}_{\text {rel, }}$ relative antigenic activity; $\Delta K$, intrinsic association constant; $\sigma$, heterogeneity index. 
town, N. Y.) and their content of lysine and $\epsilon$-N-methyl lysine determined by developing the column with a pH 5.28 buffer (11).

Immunodiffusion (Ouchterlony) Reactions.-Immunodiffusion was performed on microscope slides in $1 \%(\mathrm{w} / \mathrm{v})$ agar containing phosphate-buffered saline (pH 7.0). Antigen (100 $\mu \mathrm{g} / \mathrm{ml}$ ) was placed in the peripheral wells and undiluted, rabbit anti-flagellin antiserum in the center well. Reaction was allowed to take place at room temperature for $24 \mathrm{hr}$. The slides were then washed three times with saline and once with distilled water to remove soluble protein. Finally, the slides were dried and stained with a $0.25 \%(\mathrm{w} / \mathrm{v})$ solution of amido black in $7 \%(\mathrm{v} / \mathrm{v})$ acetic acid.

Immobilization Inhibition Test.-This technique determined the capacity of flagellin and its acetoacetylated derivatives to inhibit the immobilization of flagellated bacteria by antiflagellin antibodies. The test has been published in detail elsewhere (14).

Microprecipitin Inhibition Test.-This technique has been described in detail previously $(14,15)$. Briefly, the method measured the amount of flagellin or acetoacetylated flagellin required to inhibit the precipitation of $10 \mathrm{ng}$ of ${ }^{125} \mathrm{I}$-labeled flagellin by rabbit anti-flagellin antiserum.

Analysis of Inhibition Data.-The "relative antigenic activity" $\left(\mathrm{K}_{\mathrm{rel}}\right)$ of flagellin and its acetoacetylated derivatives was determined as follows $(16,17)$ :

$$
\mathbf{K}_{\mathrm{rel}}=\frac{\text { Amount of flagellin (50\% inhibition). }}{\text { Amount of acetoacetylated flagellin (50\% inhibition) }}
$$

$\mathrm{K}_{\mathrm{rel}}$ should approximate the reduction in the intrinsic association constant $(\Delta K)$ between flagellin and its homologous antibody caused by acetoacetylation. However, the multivalent nature of flagellin prevents $\mathrm{K}_{\mathrm{rel}}$ from being a completely accurate estimate of $\Delta K$.

Based on the assumption that $\mathrm{K}_{\mathrm{rel}} \simeq \Delta K$ the reduction in the free energy of binding between antigen and antibody was determined as follows (18):

$$
\begin{aligned}
\Delta \mathrm{F}_{\mathrm{rel}} & =\mathrm{RT} \ln \mathrm{K}_{\mathrm{rel}}, \\
& =1268 \log _{10} \mathrm{~K}_{\mathrm{rel}},
\end{aligned}
$$

if the antigen-antibody reaction reached equilibrium at $4^{\circ} \mathrm{C}$ (i.e., the microprecipitin inhibition reaction).

The "heterogeneity index" $(\sigma)$ is a probability distribution function of the free energy of interaction between antigen and antibody $(16,17)$. The larger the value of $\sigma$ the greater the heterogeneity of binding energies. Theoretically, with a $\sigma$ value of $1.0,84 \%$ of the antibody molecules have a free energy of interaction with antigen within $\pm 600 \mathrm{cal} / \mathrm{mole}$ of the mean binding energy (16). Values for $\sigma$ were determined by a curve-fitting method proposed by Pauling, Pressman, and Grossberg (16).

Antibody Estimations.-Estimations of antibody to flagellin were made in two ways: (a) by bacterial immobilization, where dilutions of sera were tested for their ability to immobilize a standard preparation of motile $S$. derby which has the same flagellar antigens $(\mathrm{fg})$ as $S$. adelaide, but has different 0 antigens $(10) ;(b)$ by a technique involving agglutination of sheep erythrocytes sensitized with polymerized flagellin using chromic chloride. This technique will be described in detail elsewhere.

Both antibody assays gave comparable antibody titers.

Statistical Methods.-Standard errors of the means and $P$ values according to the Student's $t$ test were calculated by IBM computer.

\section{RESULTS}

Acetoacetylation Reaction.--The over-all acetoacetylation reaction is presented in Fig. 1. Earlier workers $(12,13)$ demonstrated that diketene or aceto- 
acetic anhydride rapidly reacts with the $\alpha$-amino group and lysyl $\epsilon$-amino groups of proteins. In addition, the hydroxyl groups of tyrosine, threonine, and serine can become acetoacetylated when high concentrations of diketene are used.

All the acetoacetyl groups attached to proteins can be readily removed at $\mathrm{pH} 7$ by the addition of low concentrations of hydroxylamine. The acetoacetyl-<smiles>C=C1CC(=O)O1</smiles>

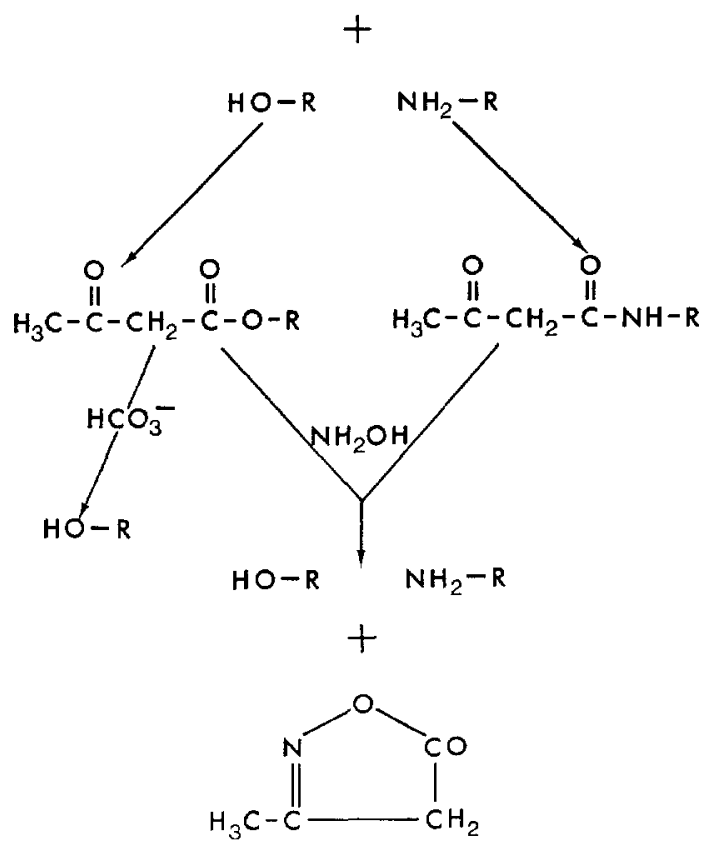

FIG. 1. The acetoacetylation reaction.

ated hydroxyl groups can be selectively unblocked by treatment with $0.2 \mathrm{M}$ carbonate-bicarbonate ( $\mathrm{pH} 9.5$ ) solution (13).

Aceloacetylation of Flagellin.-Details of the reaction conditions are described in Materials and Methods. Flagellin (mol. wt. 40,000) from S. adelaide organisms contains 26 amino groups and 77 hydroxyl groups. The detailed composition of these groupings is presented in Table I. It should be noted that in addition to lysine, flagellin contains a substantial amount of the rare amino acid, $\epsilon-\mathrm{N}$-methyl lysine.

Flagellin was reacted with molar excesses of diketene ranging from $19 / 1$ to 
$960 / 1$. The number of acetoacetyl groups attached to flagellin at each diketene concentration was estimated spectrophotometrically by measuring the absorbance of the protein at $540 \mathrm{~nm}$ in the presence of $\mathrm{FeCl}_{3}$ solution. Fig. 2 depicts the results of these spectrophotometric measurements.

As the concentration of diketene was increased there was a steady rise in the number of acetoacetyl groups attached. Approximately 15 acetoacetyl groups were readily attached to the flagellin molecule, this level of substitution being achieved by a $96 / 1$ molar ratio of diketene to flagellin. These 15 acetoacetyl groups were resistant to removal by bicarbonate solution and were therefore presumably attached to amino groups. Additional substitutions required much higher diketene concentrations, in fact, a 960/1 molar ratio produced

TABLE I

Content of Amino Acids in S. adelaide Flagellin Capable of Being Acetoacetylated

\begin{tabular}{lc}
\multicolumn{1}{c}{ Amino acid } & Residues/mole \\
\hline Alanine* & $1 \ddagger$ \\
Lysine & $14 \ddagger$ \\
$\epsilon$-N-methyl lysine & $11 \ddagger$ \\
Tyrosine & $6 \S$ \\
Threonine & $36 \S$ \\
Serine & $35 \S$ \\
Total & 103 \\
\hline
\end{tabular}

Data obtained from Parish and Ada (1969). The values are expressed as residues per mole, assuming the molecular weight of flagellin is 40,000 .

* N-terminal amino acid of flagellin.

$\$$ Available $-\mathrm{NH}_{2}$ groups $=26$.

$\S$ Available $-\mathrm{OH}$ groups $=77$.

only six additional substitutions (20.6 acetoacetyl groups/flagellin molecule). Furthermore, these additional substitutions were removed by bicarbonate, suggesting that they represented acetoacetylated hydroxyl groups (Fig. 2). In all cases approximately $90 \%$ of the acetoacetyl groups were removed by hydroxylamine solution (Fig. 2).

The extent of reaction of lysyl amino groups was also estimated by the amino acid analysis of DNFB-substituted flagellin (Fig. 3). Using this technique the extent of acetoacetylation of lysine and $\epsilon-\mathrm{N}$-methyl lysine residues was determined. Estimates of the number of acetoacetylated lysines at different diketene concentrations agree well with the spectrophotometric estimates of the number of substituted amino groups ( 15 substitutions/molecule). Thus, it appears that the $\alpha$-amino group of flagellin is not being acetoacetylated, although more direct evidence is required to prove this point.

Amino acid analysis revealed that only $8 / 14$ lysines and $7 / 11 \epsilon$-N-methyl 
lysines in flagellin could readily be acetoacetylated (Fig. 3). The susceptible methyl lysines were slightly more amenable to acetoacetylation than the reactive lysines. For comparison Fig. 3 also contains a plot of the number of acetoacetylated of groups at the different diketene concentrations, these values

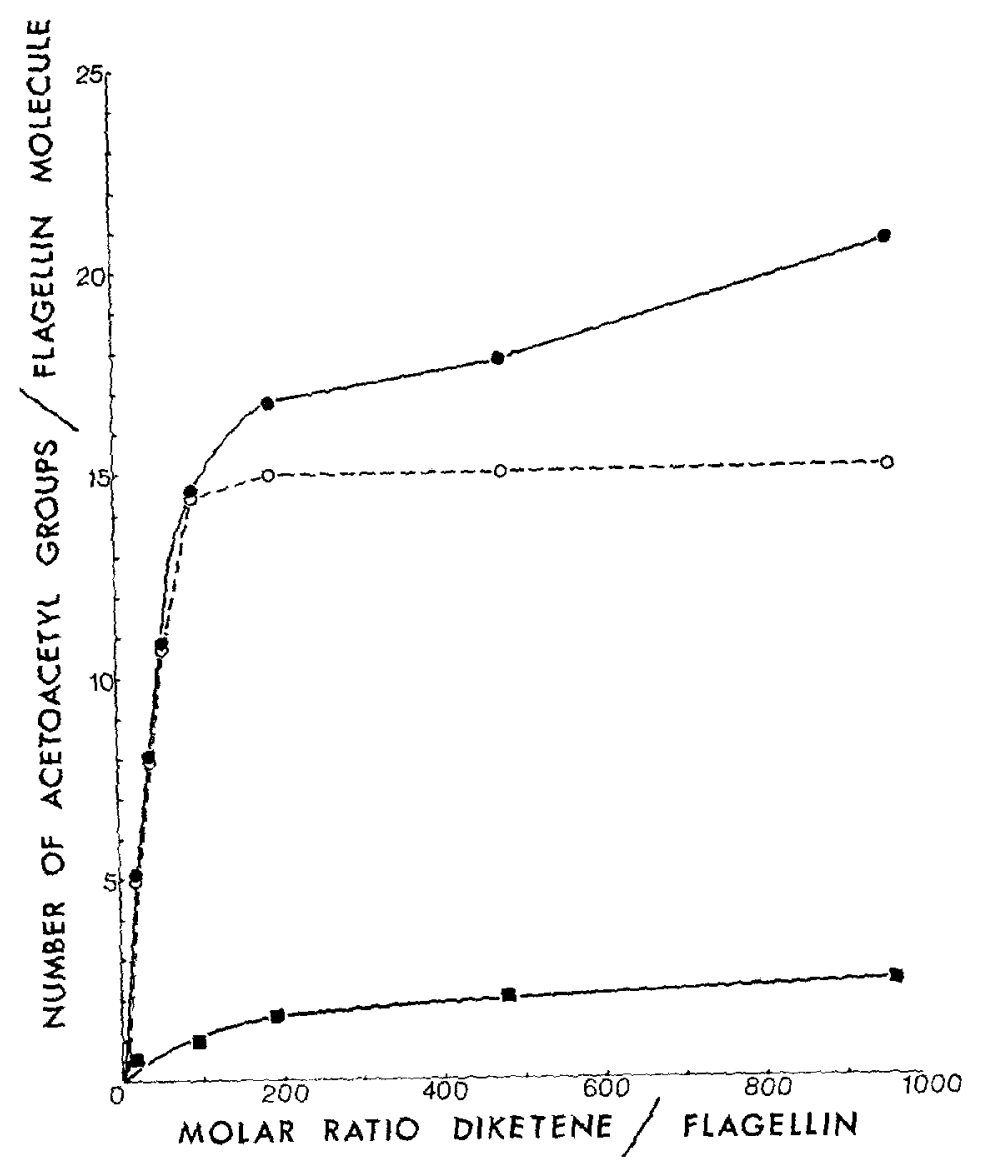

FIG. 2. Acetoacetylation of $S$. adelaide flagellin at $\mathrm{pH} 8.5$ and $20^{\circ} \mathrm{C}$. The extent of acetoacetylation was determined spectrophotometrically at $540 \mathrm{~nm}$ using $3 \% \mathrm{FeCl}_{3}$ solution. Total number of acetoacetyl groups attached (- - number of acetoacetyl groups attached after treatment with $0.2 \mathrm{NaHCO}_{3}-\mathrm{Na}_{2} \mathrm{CO}_{3}, \mathrm{pH} 9.5(\mathrm{O}-\mathrm{O}-\mathrm{O}$ ), number of acetoacetyl groups attached after $\mathrm{NH}_{2} \mathrm{OH}$ treatment ( $\left.-\mathbf{m}\right)$.

being obtained from the spectrophotometric data presented in Fig. 2. Again, it can be seen that all 15 reactive lysines in flagellin became acetoacetylated before any hydroxyl groups were substituted. The hydroxyl groups were very difficult to acetoacetylate, only 6 of the 77 hydroxyls in flagellin being substituted when a $960 / 1$ molar ratio of diketene was used. It was not established 
whether the acetoacetylated hydroxyls were derived from tyrosine, threonine, or serine residues. Substitution of the amino groups of flagellin was also monitored semiquantitatively by polyacrylamide gel electrophoresis at $\mathrm{pH} 2.7$ in $9 \mathrm{M}$ urea (11). With increasing amino group substitution there was a steady decline in the electrophoretic mobility of flagellin; in fact flagellin in which all 15 reactive lysines had been substituted did not enter the gels. No trace of unmodified flagellin could be detected in any of the preparations and all preparations which entered the gels formed narrow electrophoretic bands, an indication of highly homogeneous substitution.

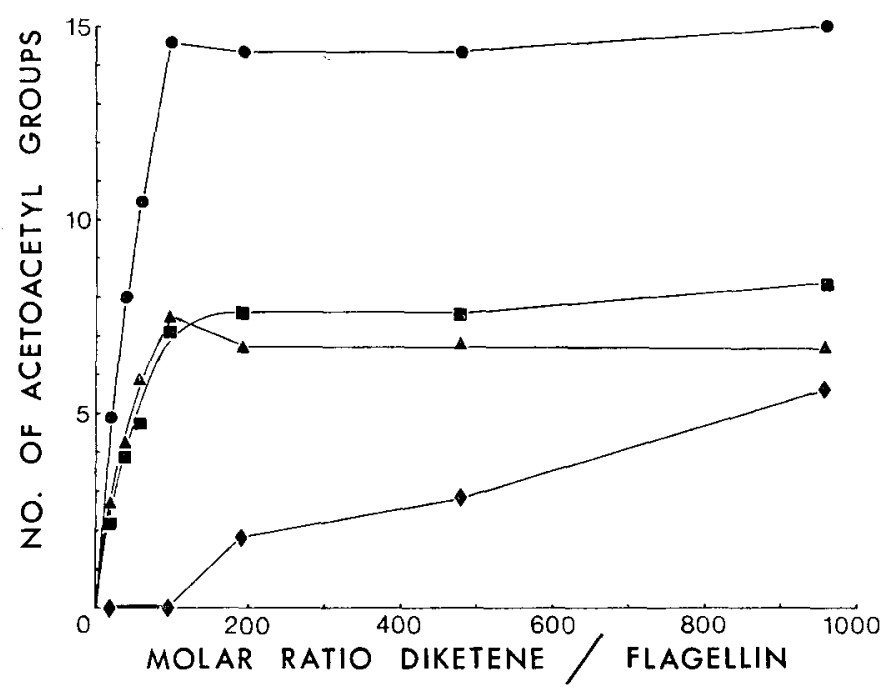

FIG. 3. Acetoacetylation of $S$. adelaide flagellin at $\mathrm{pH} 8.5$ and $20^{\circ} \mathrm{C}$. The extent $o$ acetoacetylation was determined by amino acid analysis. Total number of acetoacetylated lysines and $\epsilon-\mathrm{N}$-methyl lysines $(\bullet-\bullet)$, number of acetoacetylated lysines $(\mathbf{\square}-\mathbf{\square})$, number of acetoacetylated $\epsilon$-N-methyl lysines $(\boldsymbol{\Delta}-\mathbf{\Delta})$, number of acetoacetylated hydroxyl groups (determined spectrophotometrically) ( $\bullet$ ).

Antigenic Properties of Aceloacelylated Flagellins.--The ability of the acetoacetylated flagellins to complex with anti-flagellin antibodies was determined by double immunodiffusion, microprecipitin inhibition tests, and immobilization inhibition tests.

Double immunodiffusion (Ouchterlony) test: This technique was a qualitative test of the ability of rabbit anti-flagellin antibodies to precipitate the acetoacetylated flagellins. Attachment to flagellin of up to 10.8 acetoacetyl groups resulted in no detectable loss in precipitating activity (Fig. $4 \mathrm{~A}$ ). However, 14.6 acetoacetyl groups (96/1 preparation) produced faint spur formation. Additional substitutions enhanced spur formation and resulted in weaker and more diffuse precipitin lines (Fig. 4 B). 
Microprecipitin inhibition test: Flagellin and its acetoacetylated derivatives were tested quantitatively for their ability to inhibit the precipitation of ${ }^{125}$ I-labeled flagellin by rabbit anti-flagellin antibodies $(14,15)$.

Fig. 5 depicts the inhibition curves obtained with these antigens. In contrast to the immunodiffusion results, attachment of less than 14.6 acetoacetyl groups to flagellin did result in detectable losses in antigenic activity; in fact all the
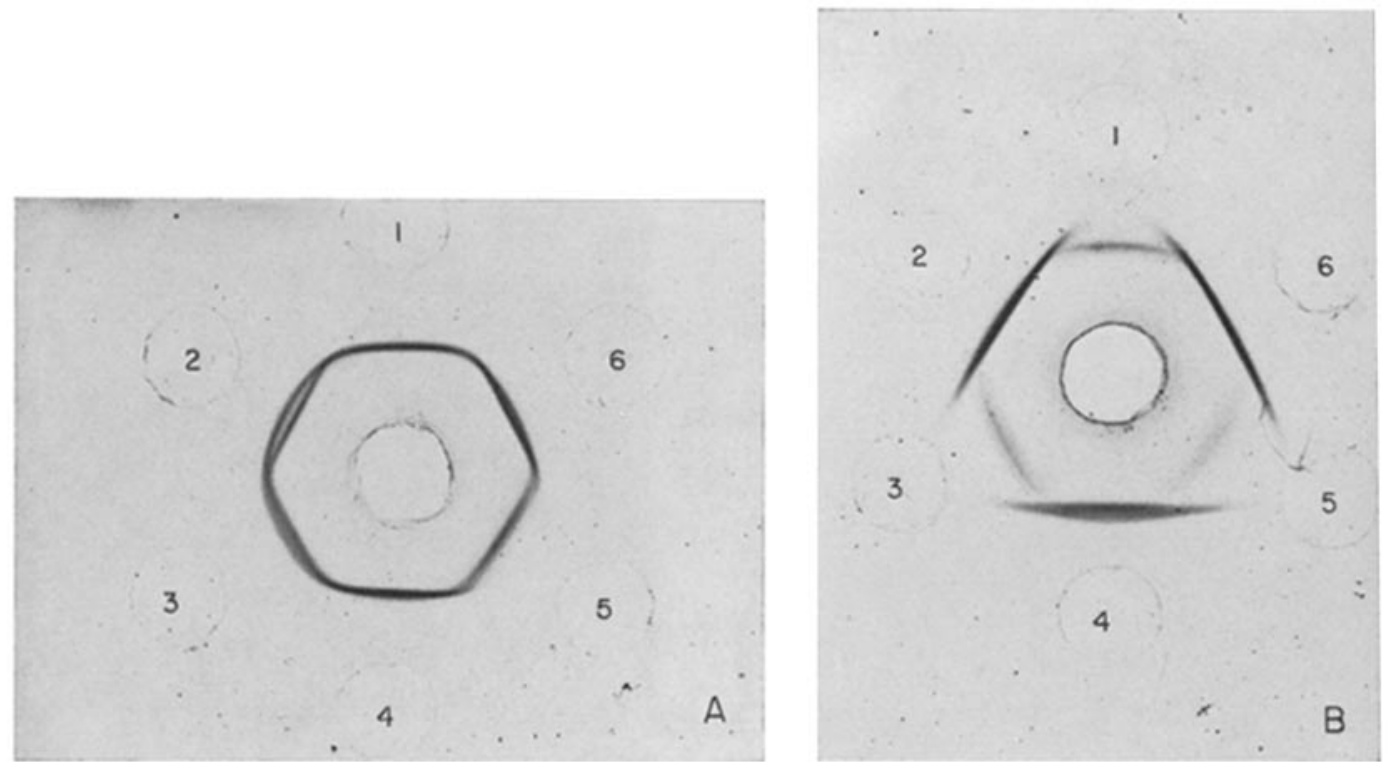

Fig. 4. Immunodiffusion reactions between the various acetoacetylated flagellins and rabbit anti-flagellin antiserum. The center wells contain the antiserum. (A) The peripheral wells contain: (1) flagellin -8.0 acetoacetyl groups; (2) unmodified flagellin; (3) flagellin-10.8 acetoacetyl groups; (4) unmodified flagellin; (5) flagellin-14.6 acetoacetyl groups; (6) unmodified flagellin. (B) The peripheral wells contain: (1) flagellin -16.8 acetoacetyl groups; (2) unmodified flagellin; (3) flagellin-17.8 acetoacetyl groups; (4) unmodified flagellin; (5) flagellin - 20.6 acetoacetyl groups; (6) unmodified flagellin.

substituted flagellins exhibited a reduced capacity to bind with anti-flagellin antibodies. There was insufficient data to determine whether flagellin substituted with $16.8,17.8$, or 20.6 acetoacetyl groups could inhibit to completion (i.e., contained all the antigenic determinants of flagellin). Moreover, the 20.6 preparation produced no detectable inhibition at the concentrations used.

In Table II the inhibition curves are analyzed in detail. The amount of each antigen which produced 50\% inhibition was determined (Table II, column 3). The $\mathrm{K}_{\text {rel }}$ of flagellin and its acetoacetylated derivatives was determined from the ratio of the $50 \%$ inhibition values (Table II). Approximate estimates of the 
reduction in the average free energy of binding $\left(\Delta \mathrm{F}_{\text {rel }}\right)$ between antigen and antibody were also obtained (Table II) (see Materials and Methods). The shapes of the inhibition curves (Fig. 5) enabled determinations of $\sigma$ to be made, $\sigma$ being an approximate index of the heterogeneity of the binding ener-

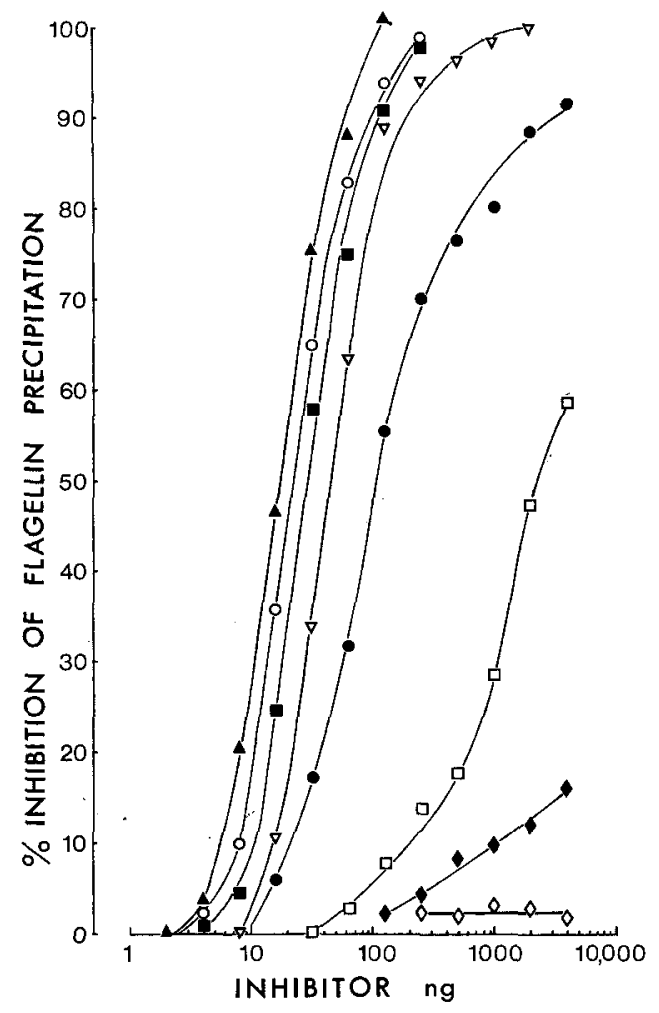

FIG. 5. The microprecipitin inhibition test. A comparison of the capacity of flagellin and the various acetoacetylated derivatives of flagellin to inhibit the precipitation of $10 \mathrm{ng}$ of ${ }^{125}$ I-labeled flagellin by rabbit anti-flagellin antibodies. The inhibition curves represent flagellin $(\mathbf{\Delta}-\mathbf{A})$ and the following numbers of acetoacetyl substitutions: $5.0(\mathrm{O}-\mathrm{O})$; $8.0(\square-\square) ; 10.8(\nabla-\nabla) ; 14.6(-\bullet) ; 16.8(\square-\square) ; 17.8(-\longrightarrow) ; 20.6$ $(\diamond-\diamond)$

gies between antigen and antibody (Table II). The larger the value for $\sigma$, the greater the heterogeneity.

As flagellin was acetoacetylated to increasing extents there was a steady decline in the affinity of flagellin for its homologous antibody (Table II). However, this reduction in affinity was not directly related to the number of acetoacetyl groups attached. Substitution with 5 acetoacetyl groups produced only a slight reduction in antigenicity $\left(\Delta \mathrm{F}_{\mathrm{rel}}=185 \mathrm{cal}\right)$, whereas acetoacetylation 
of all 15 reactive lysines (96/1 preparation) produced a much greater fall in antigenicity $\left(\Delta \mathrm{F}_{\mathrm{rel}}=1040 \mathrm{cal}\right)$ (Table II). The substitution of the reactive hydroxyl groups by higher concentrations of diketene (see earlier) resulted in very dramatic reductions in affinity. Substitution of 2.2 hydroxyl groups/mole increased the $50 \%$ inhibition value 22 -fold, 3.2 hydroxyl substitutions 10,000 -

TABLE II

Antigenic Activity of Flagellin and Its Aceloacetylated Derivatives as Measured by the Microprecipitin Inhibilion Technique

\begin{tabular}{|c|c|c|c|c|c|}
\hline Inhibitor & $\begin{array}{c}\text { No. of } \\
\text { acetoacetyl } \\
\text { groups } \\
\text { attached/ } \\
\text { mole }\end{array}$ & $\begin{array}{c}\text { Quantity of } \\
\text { inhibitor for } \\
50 \% \text { inhibition }\end{array}$ & $\begin{array}{c}\text { Relative antigenic } \\
\text { activity }\left(\mathrm{K}_{\text {rel }}\right)\end{array}$ & $\begin{array}{l}\text { Hetero- } \\
\text { geneity } \\
\text { index } \sigma\end{array}$ & $\Delta \mathrm{F}_{\mathrm{rel}}$ \\
\hline & & $n g$ & & & $c a l$ \\
\hline Flagellin & 0.0 & 17 & 1.0 & 0.25 & $0( \pm 300)$ \\
\hline $19 / 1 \S$ & 5.0 & 24 & $7.1 \times 10^{-1}$ & 0.25 & $-185( \pm 300)$ \\
\hline $38 / 1$ & 8.0 & 28 & $6.1 \times 10^{-1}$ & 0.25 & $-275( \pm 300)$ \\
\hline $\begin{array}{l}\text { CNBr digest of } \\
\text { flagellin }\end{array}$ & 0.0 & 30 & $5.7 \times 10^{-1}$ & 0.25 & $-312( \pm 300)$ \\
\hline $57 / 1$ & 10.8 & 49 & $3.45 \times 10^{-1}$ & 0.25 & $-585( \pm 300)$ \\
\hline $96 / 1$ & 14.6 & 112.5 & $1.5 \times 10^{-1}$ & 2.0 & $-1040( \pm 1200)$ \\
\hline $192 / 1$ & 16.8 & 2500 & $6.8 \times 10^{-3}$ & 3.7 & $-2750( \pm 2200)$ \\
\hline $480 / 1 \|$ & 17.8 & $1.1 \times 10^{6}$ & $1.5 \times 10^{-5}$ & $?$ & $-6100( \pm ?)$ \\
\hline $\begin{array}{r}480 / 1-\mathrm{NH}_{2} \mathrm{OH} \\
\text { unblocked }\end{array}$ & 2.0 & 36 & $4.7 \times 10^{-1}$ & 0.25 & $-418( \pm 300)$ \\
\hline $960 / 1$ & 20.6 & $2.5 \times 10^{10}$ & $6.8 \times 10^{-10}$ & $?$ & $-11700( \pm ?)$ \\
\hline
\end{tabular}

* Amount of inhibitor (ng) that gave 50\% inhibition of precipitation of $10 \mathrm{ng}$ of flagellin by rabbit anti-flagellin antiserum.

$\ddagger$ Reduction in the average free energy of binding between antigen and antibody. Values in parenthesis represent the range in binding energy of $84 \%$ of the antibody molecules (callated from $\sigma$ values). Free energy estimates are approximate rather than absolute (see Materials and Methods).

$\$$ Molar ratio of diketene to flagellin.

If $\mathbf{5 0 \%}$ inhibition values obtained by extrapolation (see text).

fold, and 6.0 hydroxyl substitutions $2 \times 10^{8}$-fold (Table II). Thus, it appears that the easily substituted lysine residues of flagellin are not intimately associated with the antigenic determinants of the molecule whereas the reactive hydroxyl groups play an important structural and/or antigenic role.

The heterogeneity index $(\sigma)$ was unaltered by the attachment of up to 10.8 acetoacetyl groups/mole (Table II). However, more extensive substitution 
rapidly increased the heterogeneity of binding energies. An important point to note is the remarkable homogeneity in the affinity of flagellin for the antiflagellin antibodies. Presumably this is because the antiserum used constitutes a single bleed from one hyperimmune rabbit.

The $50 \%$ inhibition values for flagellin substituted with 17.8 and 20.6 acetoacetyl groups were not measured directly (see Fig. 5). However, it was found that there was a linear relationship between the molar ratio of diketene: flagellin and the $\log _{10}$ of the $50 \%$ inhibition values. This relationship was probably fortuitous but enabled an estimation of the $50 \%$ inhibition values of the 17.8 and 20.6 preparations to be obtained by extrapolation (Table II). These estimated values are consistent with the inhibition data in Fig. 5. Presumably the 17.8 and 20.6 preparations have high $\sigma$ values (very heterogeneous binding energies).

Table II also summarizes the antigenic properties of $\mathrm{CNBr}$-digested flagellin and acetoacetylated flagellin (480/1 preparation) which had been unblocked by hydroxylamine. $\mathrm{CNBr}$ digestion produced a slight reduction in antigenic activity, a fact which has been reported elsewhere (14). In terms of antigenic activity, a similar preparation of flagellin was obtained by the attachment of 8.0 acetoacetyl groups/mole. Removal of the acetoacetyl groups from flagellin by hydroxylamine restored the bulk of the antigenic activity of the molecule (Table II).

Immobilization inhibition test: The ability of the acetoacetylated flagellins to inhibit the immobilization of bacteria by anti-flagellin antibodies was determined, the results being presented in Table III. As was the case with the microprecipitin inhibition technique, acetoacetylation destroyed the antigenic activity of flagellin. However, the measured losses of antigenicity were approximately 2-2.5 times greater than those estimated by the microprecipitin technique. This was probably because in the immobilization technique (a) the antigen-antibody reaction was for a very short time $(30 \mathrm{~min})$ and therefore would not have reached equilibrium, $(b)$ a subpopulation of antibody molecules may produce immobilization of bacteria, and $(c)$ the immobilization technique was performed at $20^{\circ} \mathrm{C}$ (room temperature), whereas the microprecipitin test reached equilibrium at $4^{\circ} \mathrm{C}$.

In accordance with the microprecipitin results, a $\mathrm{CNBr}$ digest of flagellin had similar antigenic activity to flagellin which had been substituted with 8 acetoacetyl groups (Table III).

In all the antigenic tests described so far, hyperimmune rabbit anti-flagellin antiserum was used. However, similar immobilization inhibition results were obtained when rat anti-flagellin antibodies were employed.

Antibody-Forming Capacity of the Acetoacetylated Flagellins.-Groups of adult 
rats (seven per group) were injected into the hind footpads with $1 \mu \mathrm{g}$ of one of the acetoacetylated flagellins in saline. Antibody titers were measured at weekly intervals and compared with those obtained in control animals which were injected with unmodified flagellin. Five wh later all animals were chal lenged with $1 \mu \mathrm{g}$ of unmodified flagellin in saline into the hind footpads and antibody titers determined up to $6 \mathrm{wk}$ postchallenge. Figs. 6 and 7 present the results of this experiment. Four different preparations of acetoacetylated flagellin were studied which had the following antigenic activities relative to flagellin

TABLE III

Antigenic Activity of Flagellin and Its Acetoacetylated Derivatives as Measured by the Immobilization Inhibition Technique

\begin{tabular}{lcccc}
\hline Inhibitor & $\begin{array}{c}\text { No. of aceto- } \\
\text { acetyl groups } \\
\text { attached/mole }\end{array}$ & $\begin{array}{c}\text { Quantity of } \\
\text { inhibitor for } 80 \% \\
\text { immobilization }\end{array}$ & $\begin{array}{c}\text { Relative antigenic } \\
\text { activity }\left(\mathrm{K}_{\text {rel }}\right)\end{array}$ & $\Delta \mathrm{F}_{\text {rel } \ddagger}$ \\
\hline $\begin{array}{l}\text { Flagellin } \\
19 / 18\end{array}$ & 0.0 & $n g$ & & $c a l$ \\
$38 / 1$ & 5.0 & 55 & 1.0 & - \\
& 8.0 & 310 & $1.8 \times 10^{-1}$ & -1000 \\
$\begin{array}{l}\text { CNBr digest of } \\
\text { flagellin }\end{array}$ & 0.0 & 275 & $2.0 \times 10^{-1}$ & -940 \\
$57 / 1$ & 10.8 & 625 & $9.1 \times 10^{-2}$ & -1420 \\
$96 / 1$ & 14.6 & 2200 & $2.5 \times 10^{-2}$ & -2140 \\
$192 / 1$ & 16.8 & 100,000 & $5.5 \times 10^{-4}$ & -4360 \\
\hline
\end{tabular}

* Amount of inhibitor (ng) that gave $80 \%$ inhibition of immobilization of motile $S$. derby (SW721) bacteria by rabbit anti-flagellin antiserum.

$\ddagger$ Reduction in the free energy of binding between antigen and antibody. Free energy estimates are approximate rather than absolute (see Materials and Methods).

$\S$ Molar ratio of diketene to fiagellin.

( $\mathrm{K}_{\mathrm{rel}}$ values): $6.1 \times 10^{-1}, 4.7 \times 10^{-1}, 3.45 \times 10^{-1}$, and $6.8 \times 10^{-3}$ (see Table II).

Acetoacetylation readily destroyed the ability of flagellin to induce a primary antibody response (Figs. 6 and 7). A 40\% reduction in the antigenicity of flagellin $\left(6.1 \times 10^{-1}\right.$ preparation) produced a $90-95 \%$ reduction in primary antibody formation. The $4.7 \times 10^{-1}$ preparation produced only a trace of antibody and the $3.45 \times 10^{-1}$ and $6.8 \times 10^{-3}$ derivatives produced no detectable primary response. Acetoacetylation also dramatically reduced the ability of flagellin to induce immunological memory (Figs. 6 and 7). Animals which had been primed and challenged with flagellin produced a mean secondary antibody titer, 7 days postchallenge, of 3600 . In contrast, rats primed with the 
$6.1 \times 10^{-1}, 4.7 \times 10^{-1}$, and $3.45 \times 10^{-1}$ flagellins, when challenged with unmodified flagellin, produced antibody titers at 7 days postchallenge of 280 , 76 , and 16 , respectively. No memory was induced by the $6.8 \times 10^{-3}$ derivative. Control animals, which had received no priming before being challenged with flagellin, gave no detectable antibody 7 days postchallenge.

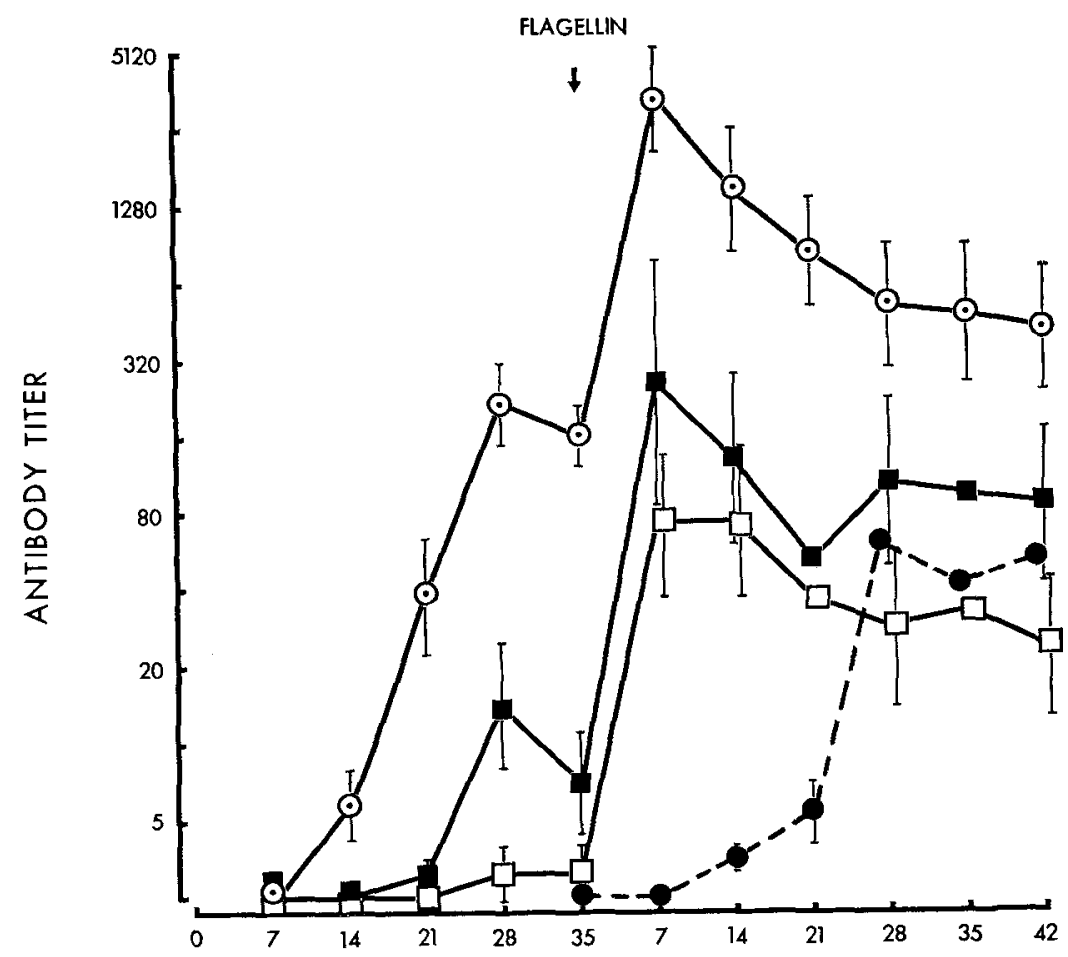

TIME AFTER CHALLENGE (DAYS)

FIG. 6. The ability of flagellin and its acetoacetylated derivatives to induce antibodies to flagellin (dose $=1 \mu \mathrm{g}$ in saline). Rats challenged on day 35 with $1 \mu \mathrm{g}$ of unmodified flagellin in saline. Legend: flagellin $(\odot-\odot)$; flagellin -8.0 acetoacetyl groups, $\mathrm{K}_{\mathrm{rel}}=$ $6.1 \times 10^{-1}(\square-\square)$; flagellin-hydroxylamine unblocked, $\mathrm{K}_{\mathrm{rel}}=4.7 \times 10^{-1}(\square-\square)$. Control rats (-- ) primed with saline and challenged on day 35 with flagellin $(1 \mu \mathrm{g})$. Vertical bars are standard errors of the means.

Secondary antibody titers were measured for 6 wk postchallenge. Animsal which had been primed $5 \mathrm{wk}$ previously with $1 \mu \mathrm{g}$ of $6.8 \times 10^{-3}$ flagellin had a very significantly reduced ability to respond to a subsequent challenge of unmodified flagellin (Fig. 7). Thus, by pretreating animals with the $6.8 \times 10^{-3}$ preparation a state of partial immunological tolerance to flagellin was induced. 
Suppression of antibody formation was of the order of $85-90 \%$ and this suppression persisted for the duration of the experiment. Although $3.45 \times 10^{-1}$ flagellin induced slight immunological memory, the 28,35 , and 42 day postchallenge titers suggested that this preparation could also induce slight toler-

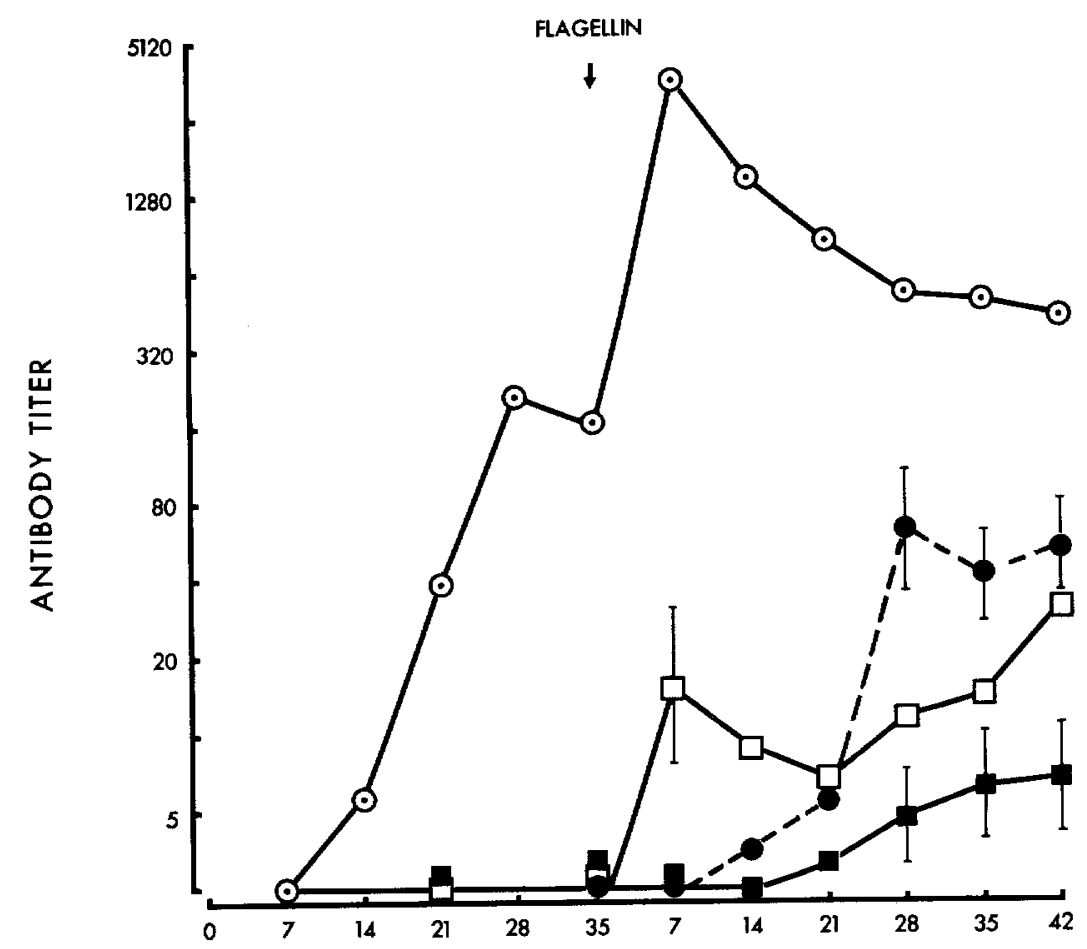

TIME AFTER CHALLENGE (DAYS)

FIG. 7. The ability of flagellin and its acetoacetylated derivatives to induce antibodies to fagellin (dose $=1 \mu \mathrm{g}$ in saline). Rats challenged on day 35 with $1 \mu \mathrm{g}$ of unmodified flagellin in saline. Legend: flagellin $(\odot-\odot)$; flagellin-10.8 acetoacetyl groups, $\mathrm{K}_{\mathrm{rel}}=3.45 \times 10^{-1}$ ( $\square-\square)$; flagellin-16.8 acetoacetyl groups, $\mathbf{K}_{\text {rel }}=6.8 \times 10^{-3}(\mathbf{\square}-\square)$. Control rats $(---\bullet)$ primed with saline and challenged on day 35 with flagellin $(1 \mu \mathrm{g})$. Vertical bars are standard errors of the means.

ance (Fig. 7). In contrast, the $6.1 \times 10^{-1}$ and $4.7 \times 10^{-1}$ flagellins produced substantial memory and not significant tolerance (Fig. 6).

Fig. 8 more clearly demonstrates the tolerance induced by the heavily acetoacetylated flagellins. In this experiment animals were injected (hind footpads in saline) $5 \mathrm{wk}$ previously with $1 \mu \mathrm{g}$ of either $6.8 \times 10^{-3}$ or $1.5 \times 10^{-5}$ flagellin, and then challenged with $1 \mu \mathrm{g}$ of unmodified flagellin in saline. Antibody 
titers were measured up to 7 wk postchallenge and compared with control animals which had been "primed" with saline. Both the $6.8 \times 10^{-3}$ and $1.5 \times$ $10^{-5}$ preparations induced highly significant tolerance $(P<0.001)$. However, the tolerance induced by these two preparations was not significantly different. In accordance with the experiment presented in Fig. 7, $6.8 \times 10^{-3}$ flagellin produced approximately $90 \%$ suppression of antibody formation. Furthermore, the antibody tolerance to flagellin appeared to be specific, rats pre-

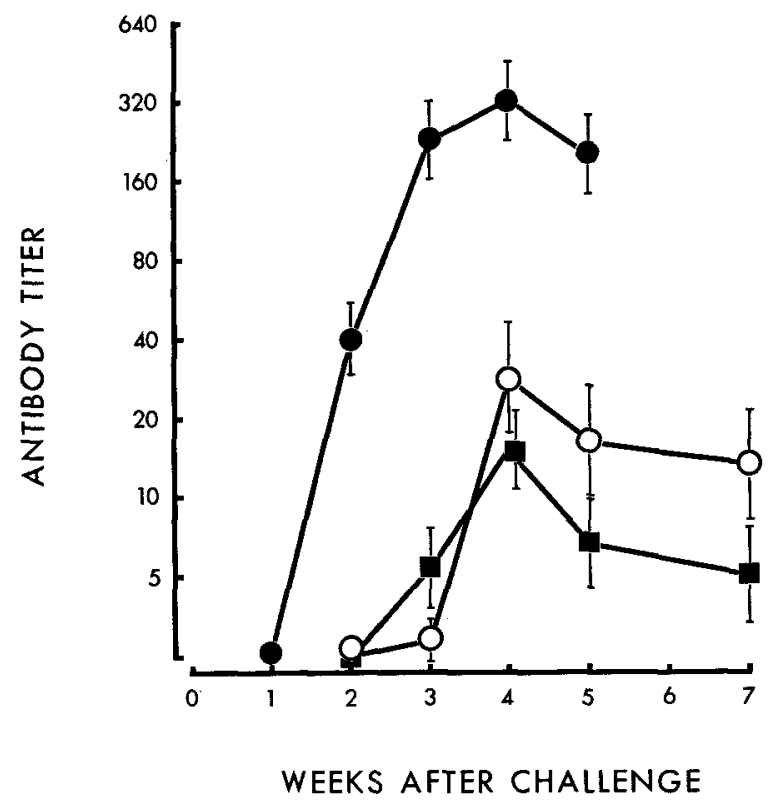

FIG. 8. The "antibody tolerance" induced by heavily acetoacetylated derivatives of flagellin. Rats challenged $5 \mathrm{wk}$ after priming with $1 \mu \mathrm{g}$ of unmodified flagellin in saline. Legend: control rats-primed with saline, challenged with flagellin $(-\ldots)$; primed with $1 \mu \mathrm{g}$ flagellin-16.8 acetoacetyl groups, $\mathrm{K}_{\mathrm{rel}}=6.8 \times 10^{-3}(\mathrm{O}-\mathrm{O})$; primed with $1 \mu \mathrm{g}$ flagellin-17.8 acetoacetyl groups, $\mathrm{K}_{\mathrm{rel}}=1.5 \times 10^{-5}(\mathbf{\square})$. Vertical bars are standard errors of the means.

treated with $1 \mu \mathrm{g}$ of $6.8 \times 10^{-3}$ flagellin producing a normal antibody response to an intraperitoneal injection of $1 \times 10^{8}$ sheep red blood cells.

Failure to Detect Antibodies Directed against Acetoacetyl Flagellin.--Sera from rats immunized with acetoacetyl flagellin were titrated against sheep red blood cells coated with the various acetoacetyl derivatives. In most cases no hemagglutinating antibodies were detected. The exceptions were the less heavily acetoacetylated preparations which induced some hemagglutinating antibodies (see Fig. 6). However, these antibodies most effectively agglutinated red cells coated with flagellin, weakly agglutinated cells coated with mildly acetoacetyl- 
ated flagellin (8.0 and 10.8 acetoacetyl groups/mole), and failed to agglutinate red cells tanned with the more heavily substituted preparations. It was demonstrated that the red cells were coated with acetoacetyl flagellin by using ${ }^{125} \mathrm{I}-$ labeled antigen. In addition no antibodies were detected which could precipitate $10 \mathrm{ng}$ of ${ }^{125} \mathrm{I}$-labeled acetoacetyl flagellin (16.8 acetoacetyl groups/mole). Under identical reaction conditions $10 \mathrm{ng}$ of ${ }^{125} \mathrm{I}$-flagellin was readily precipitated by rat anti-flagellin antibodies. The procedure was a modification of the microprecipitin technique (15).

\section{DISCUSSION}

It was demonstrated many years ago that extensive substitution of protein antigens by a wide range of reagents destroyed serological specificity (see reference 19). However, the ability of these substituted proteins to induce antibody formation has been frequently overlooked and their capacity to induce immunological tolerance to the unmodified protein has rarely been studied. Results presented in this paper demonstrate that acetoacetylation of the flagellin molecule also destroys antigenic activity. This loss in antigenic activity was accompanied by a fall in antibody-forming capacity and the conversion of flagellin into a molecule with strong tolerance-inducing properties.

Flagellin was readily acetoacetylated under mild conditions. These acetoacetylation studies confirmed the findings of other workers that the amino groups of proteins are much more easily acetoacetylated than the hydroxyl groups (12). However, only 15 of the 25 lysines in flagellin could be acetoacetylated, whereas earlier studies have demonstrated that all of the lysines in ribonuclease (12) and lysozyme (13) can be substituted.

Two types of antibody assays were used to study the antigenic properties of flagellin and its acetoacetylated derivatives. Firstly, the precipitin reaction was used either in a qualitative manner as simple immunodiffusion or as a quantitative microprecipitin inhibition reaction. Secondly, the technique of bacterial immobilization was used for inhibition studies. Several conclusions can be drawn from these antigenic tests.

(a) As flagellin was acetoacetylated to increasing extents there was a steady decline in its affinity for anti-flagellin antibodies. From the inhibition results estimates of the changes in the free energy of binding between antigen and antibody were determined.

(b) Antigenic activity was not related to the number of acetoacetyl groups attached, but was determined by the type of residue substituted. Reactive lysine residues were much less important antigenically than easily substituted hydroxyl groups.

(c) The heavily acetoacetylated flagellins had a very wide distribution of binding energies for anti-flagellin antibodies.

(d) The bulk of the antigenic activity of flagellin was restored when the acetoacetyl groups were removed by hydroxylamine. 
It was difficult to determine from the antigenic tests whether extensive acetoacetylation resulted in selective loss of antigenic determinants or in destruction of all determinants at a similar rate. Spur formation observed in the immunodiffusion reaction (Fig. $4 \mathrm{~B}$ ) could be due to incomplete neutralization of all species of anti-flagellin antibodies by the acetoacetylated flagellins, rather than selective loss of determinants.

The immunogenicity studies demonstrated that acetoacetylation very readily destroyed the antibody-forming capacity of flagellin. However, this fall in immunogenicity was not related to the number of acetoacetyl groups attached but was determined by the antigenic activity of the preparations (i.e., the affinity of the acetoacetyl flagellins for anti-flagellin antibodies). This phenomenon was most clearly demonstrated by hydroxylamine unblocked flagellin (Table II), which carried only 2 acetoacetyl groups/mole, but which had antigenic and immunogenic properties similar to flagellin that had been substituted with between 8 and 10.8 acetoacetyl groups (Fig. 6).

An important point to note is the dramatic change in the immunogenicity of flagellin following only minor changes in antigenic activity. The association constants for most antibody-hapten systems are about $10^{5} \mathrm{M}^{-1}$ (approximately $6000 \mathrm{cal}$ ) (20), although association constants as high as $10^{10} \mathrm{M}^{-1}$ (approximately $13,000 \mathrm{cal}$ ) have been measured (21). Similar affinity constants have been obtained with protein antigens (20). Thus, it seems reasonable to assume that the flagellin-anti-flagellin reaction has an association constant somewhere within this range. However, a $40 \%$ reduction in the antigenicity of flagellin $\left(\mathrm{K}_{\mathrm{rel}}=6.1 \times 10^{-1}, \Delta \mathrm{F}_{\mathrm{rel}}=-275 \mathrm{cal}\right)$ produced a $90-95 \%$ reduction in the antibody-forming capacity of the molecule. It can be concluded from this result that the affinity of antigen for the receptors on cells appears to be of crucial importance in determining whether antibody formation occurs. In contrast, immunological tolerance to flagellin was induced by acetoacetylated flagellins which had drastically reduced antigenicity (i.e., $\mathrm{K}_{\mathrm{rel}}=1.5 \times 10^{-5}$, $\left.\Delta \mathrm{F}_{\mathrm{rel}}=-6,100 \mathrm{cal}\right)$. One would expect these preparations to be unrecognizable as flagellin. However these derivatives have a very broad spectrum of binding energies, their immunological properties possibly being due to molecules with affinities close to that of flagellin.

There was no evidence that acetoacetylation converted flagellin into a new antigen which was capable of producing antibodies with a completely different spectrum of specificities. No antibodies could be detected which could precipitate heavily acetoacetylated flagellin or agglutinate sheep red blood cells coated with acetoacetylffagellin. Of course, these techniques would not detect small quantities of low affinity antibody.

It has been demonstrated previously in this laboratory that $\mathrm{CNBr}$ digestion destroys the antibody-forming capacity of flagellin but enhances the toleranceinducing properties of the protein $(8,9)$. Now it appears that by a process of acetoacetylation even stronger tolerance-inducing preparations of flagellin 
can be obtained. In fact, tolerance was only induced by multiple doses of the $\mathrm{CNBr}$ digest of flagellin $(8,9)$, whereas a single, $1 \mu \mathrm{g}$ dose of acetoacetylated flagellin induces good suppression of antibody formation. Presumably the altered immunological properties of $\mathrm{CNBr}$-digested flagellin are due to a slight loss of antigenic activity resulting from $\mathrm{CNBr}$ degradation (see Table II). Flagellin substituted with 8 acetoacetyl groups has similar antigenic properties to the $\mathrm{CNBr}$ digest. In the following paper (22) it will be demonstrated that these two preparations of flagellin do, in fact, have identical immunological properties.

It seems quite possible that acetoacetylation of many other protein antigens would also produce preparations with strong tolerance-inducing properties. In this paper no attempt has been made to interpret the results presented in terms of the inductive events required for antibody formation and immunological tolerance. These interpretations will be presented in detail in the following paper (22) where it will be demonstrated that acetoacetylation dramatically enhances the ability of flagellin to induce cell-mediated immunity.

SUMMARY

Flagellin (mol. wt. 40,000) from S. adelaide organisms was acetoacetylated to varying extents with diketene (acetoacetic anhydride). Chemical studies demonstrated that the amino groups of flagellin were more readily acetoacetylated than the hydroxyl groups. Several antigenic tests revealed that as flagellin was acetoacetylated to increasing extents there was a steady decline in the affinity of the molecule for anti-flagellin antibodies.

Loss in antigenic activity following acetoacetylation was not related to the number of acetoacetyl groups attached but was determined by the type of residue substituted. Reactive lysine residues were much less important antigenically than easily substituted hydroxyl groups.

Acetoacetylation very readily destroyed the antibody-forming capacity of flagellin in rats. This fall in immunogenicity was related to the antigenic activity of the preparations. In fact, only a $40 \%$ reduction in the antigenic activity of flagellin produced a $90-95 \%$ reduction in primary antibody formation. The more heavily acetoacetylated flagellins produced no detectable antibody and, in fact, rendered adult rats tolerant (in terms of antibody formation) to a subsequent challenge of flagellin. Tolerance was induced by acetoacetylated flagellins which had drastically reduced affinities for anti-flagellin antibodies.

These results were interpreted as indicating that the affinity of antigen for receptors on cells appears to be of crucial importance in determining whether antibody formation or immunological tolerance (antibody suppression) occurs.

The author gratefully acknowledges the encouragement and advice of Professor G. L. Ada and Mr. F. Y. Liew and the excellent technical assistance of Mr. R. Tha Lha. 


\section{REFERENCES}

1. Sela, M. 1966. Immunological studies with synthetic polypeptides. Advan. Immunol. 5:29.

2. Kabat, E. A., and M. M. Mayer. 1961. Kabat and Mayer's Experimental Immunochemistry. Charles C Thomas, Publisher. Springfield, Ill. 2nd edition.

3. Kabat, E. A. 1966. The nature of an antigenic determinant. J. Immunol. 97:1.

4. Luderitz, O., A. M. Staub, and O. Westphal. 1966. Immunochemistry of $O$ and R antigens of Salmonella and related Enterobacteriaceae. Bacteriol. Rc2. 30:192.

5. Maurer, P. H. 1964. Use of synthetic polymers of amino acids to study the basis of antigenicity. Progr. Allergy. 8:1.

6. Sela, M. 1969. Antigenicity: some molecular aspects. Science (Washington). 166:1365.

7. Nossal, G. J. V., G. L. Ada, and C. Austin. 1964. Antigens in immunity. II. Immunogenic properties of flagella, polymerized flagellin and flagellin in the primary response. Aust. J. Exp. Biol. Med. Sci. 42:283.

8. Ada, G. L., and C. R. Parish. 1968. Low zone tolerance to bacterial flagellin in adult rats: a possible role for antigen localized in lymphoid follicles. Proc. Nat. Acad. Sci. U.S.A. 61:556.

9. Parish, C. R., and G. L. Ada. 1969. The tolerance inducing properties in rats of bacterial flagellin cleaved at the methionine residues. Immunology. 17:153.

10. Ada, G. L., G. J. V. Nossal, J. Pye, and A. Abbott. 1964. Antigens in immunity. I. Preparation and properties of flagellar antigens from Salmonella adelaide. Aust. J. Exp. Biol. Med. Sci. 42:267.

11. Parish, C. R., and G. L. Ada. 1969. Cleavage of bacterial flagellin with cyanogen bromide. Chemical and physical properties of the protein fragments. Biochem. $J$. 113:489.

12. Marzotto, A., P. Pajetta, and E. Scoffone. 1967. Acetoacetylation of ribonuclease A. Biochem. Biophys. Res. Commun. 26:517.

13. Marzotto, A., P. Pajetta, L. Galzigna, and E. Scoffone. 1968. Reversible acetoacetylation of amino groups in proteins. Biochim. Biophys. Acta. 154:450.

14. Parish, C. R., R. Wistar, and G. L. Ada. 1969. Cleavage of bacterial flagellin with cyanogen bromide. Antigenic properties of the protein fragments. Biochem. $J$. 113:501.

15. Wistar, R. 1968. Serum antibody to Salmonella flagellar antigen. I. Methods of antibody assay. Aust. J. Exp. Biol. Med. Sci. 46:769.

16. Pauling, L., D. Pressman, and A. L. Grossberg. 1944. The serological properties of simple substances. VII. A quantitative theory of the inhibition by haptens of the precipitation of heterologous antisera with antigens, and comparison with experimental results for polyhaptenic simple substances and for azoproteins. J. Amer. Chem. Soc. 66:784.

17. Pressman, D. 1964. Hapten-antibody combination determined by inhibition of precipitation. In Methods in Medical Research. H. P. Eisen, editor. Year Book Medical Publishers, Inc., Chicago. 10:122.

18. Schubert, D., A. Roman, and M. Cohn. 1970. Anti-nucleic acid specificities of mouse myeloma immunoglobulins. Nature (London). 225:154. 
19. Landsteiner, K. 1945. The Specificity of Serological Reactions. Harvard University Press, Cambridge.

20. Singer, S. J. 1965. Structure and function of antigens and antibodies. In The Proteins. H. Neurath, editor. Academic Press, Inc., New York. 3:269.

21. Smith, T. W., V. P. Butler, and E. Haber. 1970. Characterization of antibodies of high affinity and specificity for the digitalis glycoside digoxin. Biochemistry. 9:331.

22. Parish, C. R. 1971. Immune response to chemically modified flagellin. II. Evidence for a fundamental relationship between humoral and cell-mediated immunity. J. Exp. Med. 134:21. 